\title{
The E-HEALTh ReVolution AND THE NECESSARY EVOLUTION OF INFORMED CONSENT
}

\author{
Jessica Berg, JD, MPH ${ }^{1}$
}

I. BACKGROUND ....................................................591

A. Informed Consent ..........................................591

B. Rise of $E$-Health.............................................594

II. The Consumer E-Health UnIVERSE .........................595

A. E-Health and Shared Decision Making................595

B. E-Health Substitutes for Clinical Encounters ......600

III. IMPLICATIONS OF THE NEW E-MEDIA FOR INFORMED

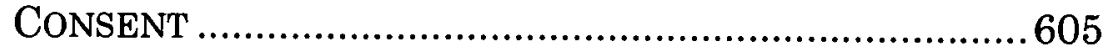

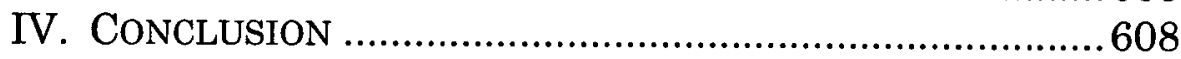

In the past decade the e-health revolution has transformed the practice of medicine. While there has been a great deal of focus on the implications of the development of new e-media ${ }^{2}$ for the provision of medical care, less attention has been paid to the implications for informed consent. Long considered a core practice in medical ethics, informed consent's framework and role in the internet age is less clear. New mechanisms for information sharing have the potential to transform the traditional practice of both disclosure and consent.

1 Interim Dean and Professor of Law, Bioethics and Public Health. Case Western Reserve University. I would like to thank Tracy $\mathrm{Li}$ for her excellent research assistance, the Department of Bioethics work-in-progress participants for their helpful comments, and Sharona Hoffman for her suggestions. All errors and omissions are my own.

2 E-media, or electronic media, is defined broadly to include any media that uses electronics (digital or analog) to reach end-users. This is in contrast to either print media or real life face-to-face interactions. E-media can include video, audio, multi-media, cell-phone, computer, or handheld devices. 
Informed consent for treatment is a judicially created doctrine developed in the Civil Rights Era. ${ }^{3}$ The doctrine is premised on the concept that not only do individuals have a right to decide what happens to their bodies, but that individual goals, not simply medical goals, should drive treatment choices. To afford patients the information necessary to make these choices, healthcare professionals are given the responsibility (and legal duty) to provide education about medical treatment options. But the original model rests on a construct in which the healthcare professional (at the time, mostly physicians) retained significant control over medical information and resources. In fact, before the development of the doctrine of informed consent, not only were patients not involved in choosing a treatment, they often were not even told their diagnosis. There are debates about whether the original doctrine of informed consent weighed too heavily in favor of autonomy over beneficence. But it did so against a history in which patient played almost no role in medical decision making, and, thus, an effort to overcompensate is understandable.

Fast-forward half a century and our world looks very different. With the advent of e-medical diagnostic tools, direct-to-consumer advertisements, over-the-counter access to medications, and individually controlled genetic testing, the model of control has started to shift away from physicians. At the same time, we continue to push the concept of autonomous decision making into situations in which it may less easily function. New structures of healthcare delivery rely on fully informed patients making choices based on complex quality and cost data, with little understanding about the limitations of informed consent in this context. Patients are regarded as consumers of healthcare, much as people are thought to be consumers of other goods and services. Less attention is paid to whether information sharing and informed consent can live up to the goals we currently set for them. Not only do we expect individuals to incorporate increasing amounts of complex information into their decisions (including information that

3 Jessica W. Berg et AL., INFORMed CONSENT: LEGAL THEORY AND ClinICAL PRACTICE (2d ed. 2001). 
is provided outside of the traditional patient-physician relationship), we see a growing effort to place individual responsibility on people for maintaining their health. In some cases we even blame patients for what are seen as poor choices, such as obesity. What role can and should informed consent play in the current system? Should healthcare professionals still have the same disclosure obligations in the information overload of the internet world? How can the new technologies help facilitate information transfer, and how should the legal doctrine accommodate such changes? After providing a brief background on informed consent, this Article explores the proliferation of e-health technologies and introduces some of their ethical and legal implications. It will focus on two areas: use of e-health ${ }^{4}$ tools to supplement traditional informed consent practices, and the use of e-health technologies to replace traditional medical interactions.

\section{BACKGROUND}

\section{A. Informed Consent 5}

A doctrine judicially created in the late 1960's and early 1970's, informed consent has become a standard part of medical practice. ${ }^{6}$ It is an interesting question whether the judicial doctrine drove the ethical one or vice versa. Prior to development of the judicial doctrine, consent played little or no role in standard medical practice. Unlike, for example, the doctrine of confidentiality, which has a long history in medicine, informed consent does not show up in ethical

4 There are both provider and consumer e-health tools. This paper focuses on the latter, e.g., "a broad category of electronic tools and services that are primarily consumer oriented but that overlap with health information technology, a term more conventionally used in the context of technology for health care providers." Lygeia Ricciardi et al., A National Plan to Support Consumer Engagement Via E-Health, 32 HEALTH AFF. 376, 384 (2013).

5 See generally Jessica Berg, All for One and One for All: Informed Consent and Public Health, 50 Hous. L. REV. 1 (2012).

6 See JESSICA W. BERG ET AL., supra note 3. 
codes until late in the twentieth Century. ${ }^{7}$ Regardless of its origins, informed consent now forms the bedrock of clinical bioethics. It is not, however, without its critics. While the principle of autonomy drives much of the bioethics discourse, many commentators have pointed out the need to balance autonomy against other interests and incorporate other ethical approaches besides the principalist one upon which the doctrine of informed consent appears to be based. 8 Autonomy is a Western (and distinctly American) value and may not fit well within other cultures and practices. ${ }^{9}$ Even under a principalist approach to bioethical issues in medicine, ${ }^{10}$ the principle of autonomy may sometimes be outweighed by the principle of justice, which can limit the distribution of scarce medical resources regardless of individual preferences, ${ }^{11}$ or the principle of autonomy may be outweighed by the principle of beneficence, which may weigh in favor of treatment even over the individual's objections. Others have pointed out

$7 \quad I d$. Informed consent for research developed separately from informed consent for medical practice, and its current structure is based on federal regulations. A full analysis of the development of the informed consent doctrine is beyond the scope of this piece.

$8 \quad I d$. at $32-35$. Principalism identifies the key principles which should drive ethical action (in medicine this is usually autonomy, beneficence, nonmaleficence and justice). See, e.g., TOM L. BEAUCHAMP \& JAMES E.CHILDRESS, PRINCIPLES OF BIOMEDICAL ETHICS (7th ed. 2012). Informed consent developed from the promotion of the principle of autonomy (allowing individuals choice over what happens to them), as well as the principle of beneficence (individuals are deemed to be the best able to judge what in in their own interests and will be of the most benefit).

9 Charles E. Schneider, The Practice of Autonomy: Patients, DOCTORS, AND MEDICAL DECISIONS (1998).

10 See, e.g., TOM L. BeaUChamp \& James F. ChILDRESS, PRINCIPLES OF BIOMEDICAL ETHICS (6th ed. 2009). A principalist approach identifies a series of core principle which should guide medical practice. According to the version proposed by Beauchamp and Childress, the principles include autonomy, nonmaleficence, beneficence, and justice. In many applications of the principalist approach the principle of autonomy seems paramount.

11 Justice concerns (sometimes referred to as fairness or equality) may limit the distribution of scarce resources. In such cases we may limit the types of choices the individual can make to ensure a more just distribution across society. 
that even if autonomy is, or should be, a primary value in our society, there are limits to the extent to which we can expect patients to make fully autonomous decisions. Individuals do not function in a vacuum and rarely make decisions without input and advice from various people (e.g., family, friends, and sometimes experts). Moreover, the fact that someone may make a decision, even an important one, without fully considering all of the relevant information does not mean we should not give it respect and weight. Part of being an autonomous individual is having the right to make decisions without full information. Additionally, there is a growing psychological literature which indicates that decision making can be influenced in a variety of ways, including simply by the way in which certain information is disclosed. ${ }^{12}$ I will return to this point later.

Informed consent, while often referred to as a unitary concept, is really made up of two requirements: a duty to disclose information and a right to make decisions. To meet the information requirement, physicians must disclose basic information about the patient's diagnosis and treatment options along with their risks, benefits, and alternatives. The patient is asked to either consent to or refuse the treatment (in this sense, "informed choice" may be a better name for the doctrine than "informed consent" since refusals must also be informed).13 The established exceptions include incompetence, ${ }^{14}$ waiver, ${ }^{15}$ emergencies, therapeutic privilege, and some public health ${ }^{16}$ interventions. The vast literature and extensive case law on informed consent will not be rehashed here. ${ }^{17}$

12 See, e.g., Daniel Kahneman, Thinking, FAST AND Slow (2011).

13 BERG ET AL., supra note 6.

14 See Jessica W. Berg et al., Constructing Competence: Formulating Standards of Legal Competence to Make Medical Decisions, 48 RuTGERS L. REV. 345 (1996).

15 Jessica W. Berg, Understanding Waiver, 40 Hous. L. REv. 281 (2003).

16 Berg, supra note 3.

17 Id. 
Why require individual informed consent? Consent theorists offer a number of reasons. ${ }^{18}$ First, individuals are most likely to know their interests and thus make better choices for their health and well-being. Second, the information requirement may increase the likelihood that the intervention will be beneficial since the individual better understands what to expect, including being prepared to recognize problems that may arise. Third, even if individuals err in their choices, we are better off as a society if we encourage individual decision making and, thus, develop autonomous citizens. Fourth, individuals have a right to control what happens to their bodies.

\section{B. Rise of E-Health}

In fact, it is this focus on individual control over self and the benefits which may flow from promoting autonomy that have prompted many of the technological advances in consumer e-health. Various studies over the past decade have focused on developing mechanisms to facilitate patient engagement in their medical care to achieve better health outcomes. ${ }^{19}$ The 2001 Institute of Medicine report "Crossing the Quality Chasm: A New Health System for the 21 Century," emphasized that information technology ("IT") should play a significant role in achieving this goal. ${ }^{20}$ The report noted that, among other things, IT can do the following:

- Facilitate access to more understandable clinical knowledge;

- Afford more timely information sharing through internet based communication tools;

18 BERG ET AL., supra note 7, at 18; see also FADEN \& BEAUCHAMP, A HiSTORY AND THEORY OF INFORMED CONSENT 7-16 (1986) (including also the principle of justice, but noting that " $[t]$ he major moral and conceptual problems about informed consent are not justice-based and do not directly confront issues of social justice").

19 See studies cited in Ricciardi, supra note 3 at 377.

20 INST. OF MED., COMM. ON QUALITY OF HEALTH IN AM., CROSSING THE QUALITY CHASM: A NEW HEALTH SYSTEM FOR THE 21ST CENTURY 4164 (2001). 
- Improve efficiency by coordinating information in one place and avoiding redundancies; and

- Enhance equity by allowing for multiple options for clinical interactions. ${ }^{21}$

Research exploring the benefits of e-heath determined that "[p]eople who use e-health resources feel better prepared for clinical encounters, ask more relevant questions, know more about their health care, and are more likely to take steps to improve their health, compared to those who do not." 22 As more people use e-health tools there should be a greater effect on the system. According to current estimates, " 80 percent of US internet users have searched for health information online... 34 percent of internet users have read about other people's health and medical experiences online, and 18 percent of internet users have gone online to find others who share their health condition or concern." 23

\section{The Consumer E-Health Universe}

The e-health universe is extensive and a full analysis of all of the new technologies is beyond the scope of this article. For our purposes, there are two primary developments of interest. The first is the use of e-health technology to promote the shared decision making model, as a supplement to traditional informed consent. The second is the use of e-health technology as a substitute for clinical encounters. The following sections will address each of these in turn.

\section{A. E-Health and Shared Decision Making}

21 Id. at $164-165$.

22 Id. (footnotes omitted).

23 Lygeia Ricciardi et al., A National Action Plan to Support Consumer Engagement Via E-Health, 32 HEALTH AFF. 376, 378 (footnotes omitted). The authors also posit that the limits of e-health use are based not on lack of interest, but lack of access to the internet and that the appeal of e-health crosses a wide array of age, gender, and diversity lines. Id. at 377 . 
While the idea of shared decision making in informed consent is not new, ${ }^{24}$ the development of the "shared decision making" ("SDM") model is more recent. ${ }^{25}$ The model is premised on the assertion that the "emphasis on patient autonomy in medical-decision making can go too far"26 and that "[d]emonstrating respect for patient autonomy does not require physician to remain neutral sources of information in the care of their patients." 27 Rather than have the physician provide all information and the patient make a decision without input, a better approach would be to emphasize the shared aspects of decision making. As a result, the SDM approach involves a process of communication in which the physician and patient both evaluate together the patient's medical goals, life preferences, and risks/benefits of all viable treatment alternatives. ${ }^{28}$ Some commentators have noted that the SDM terminology can encompass a wide variety of concepts and fall under a range of labels; "[f]or instance, its features have been referred to as informed decision-making, informed shared decision-making, partnership, patient involvement, patient-centered care, and evidence-based patient choice." 29

24 See, e.g., President's Comm'n, President's Comm'n for the Study of Ethical Problems in Med. and Biomedical and Behavioral Research, Making Health Care Decisions: The Ethical and Legal Implications of Informed Consent in the Patient-Practitioner Relationship (1982), available at https://bioethicsarchive.georgetown.edu/pcbe/reports/past_commissions/mak ing_health_care_decisions.pdf ("[T]he Commission sees 'informed consent' as an ethical obligation that involves a process of shared decision making based upon the mutual respect and participation of patients and health professionals. ... Ethically valid consent is a process of shared decision making based upon ritual to be equated with reciting the mutual respect and participation."), archived at http://perma.cc/A6VL-52VK.

25 Benjamin Moulton \& Jaime S. King, Aligning Ethics with Medical Decision-Making: The Quest for Informed Patient Choice, $38 \mathrm{~J}$. L. MED. \& ETHICS 85 (2010).

$\begin{array}{ll}{ }_{26} & I d \text {. at } 88 . \\ { }_{27} & I d \text {. at } 89 . \\ & I d .\end{array}$

29 Nora Moumjid et al., Shared Decision-Making in the Medical Encounter: Are We Talking about the Same Thing, 27 MED. DECISION MAKING 539 (2007) ("Likewise, the term shared decision-making has 
A key to the implementation of SDM involves the use of decision support tools (in some cases multiple tools) to supplement the conversations between physician and patients. The "patient decision aids" are supposed to be standardized, evidence-based tools. ${ }^{30}$ While they may take a variety of forms, including print, audio, or video media, there is a current shift toward internet-based technology. ${ }^{31}$ Although the goal of the SDM tools is to supplement the clinical informed consent process, "[m]any, if not most, patient decision support interventions have designs that make it possible for patients to use them independently of the clinical encounter because they contain comprehensive information and guidance." 32 Nonetheless, they are not intended to be freestanding tools; their focus, instead, is on helping the patient identify his or her preferences, goals, and questions prior to the informed consent dialogue with the healthcare provider. ${ }^{33}$

The SDM model raises various issues for the legal doctrine of informed consent but does not necessarily challenge the underlying framework. Others have addressed these issues in detail and their work will not be repeated here. Nadia Sawicki explores the tort law

been used to mean many different things, such as a process requiring mutual agreement between patient and physician or a method of providing information to the patient and then leaving the patient to make her own decision.").

30 Annette M. O'Connor et al., Modifying Unwarranted Variations in Health Care: Shared Decision Making Using Patient Decision Aids, 23 HEALTH AFF. VAR-63, VAR 64 (2004).

31 Id. The most useful models incorporate a number of different tools. For example, the Dartmouth SDM model uses (1) a video decision aid, (2) an online survey and written questionnaire, (3) optional additional resources for resolving conflict, (4) a SDM communication process, and (5) a post-treatment survey. See Moulton \& King, supra note 25 , at 91 (describing the model).

32 Glen Elwyn et al., Investing in Deliberation: A Definition and Classification of Decision Support Interventions for People Facing Difficult Health Decisions, 30 Med. Decision Making 701, 702 (2010).

33 Thaddeus Mason Pope \& Melinda Hexum, Legal Briefing: Shared Decision Making and Patient Decision Aids, 24 J. ClinICAL ETHICS 70, 71 (2013). 
implications of SDM in her 2012 articles, ${ }^{34}$ and others, such as Thaddeus Pope and Melinda Hexum, have followed up with a discussion of a range of other legal issues raised by the use of SDM tools. ${ }^{35}$ They conclude that we must do a better job at assuring quality in this context by developing clear standards and certification mechanisms for the tools, address how provider reimbursement will work when using the tools, and expand research regarding the effectiveness of the tools. There are also some interesting questions about how courts will respond to the use of the tools in altering traditional informed consent liability. For example, Washington state enacted legislation in 2007 making the use of a SDM tool prima facie evidence of legally valid informed consent. While a traditional signed informed consent form likewise constitutes prima facie evidence, the SDM tool creates a heavier burden of rebuttal for any patient seeking to challenge informed consent as inadequate. Thus a patient would have to show negligence by clear and convincing evidence that consent was not informed, instead of the usual preponderance of the evidence. $^{36}$ Washington also recently enacted legislation encouraging the use of SDM aids and proposed a process for certifying decision aids. ${ }^{37}$ Other states have passed or are considering similar laws. ${ }^{38}$

Building upon the initial efforts to create SDM tools, some companies have been developing fully online consent systems. Emmi Solutions, a healthcare communication company, developed an interactive e-consent program called Emmi Engage deliverable over the web and via mobile devices. ${ }^{39}$ Dialog Medical has its iMedConsent, ${ }^{40}$ which was

34 See Nadia N. Sawicki, Informed Consent Beyond the PhysicianPatient Encounter: Tort Law Implications of Extra-Clinical Decision Support Tools, 21 ANNALS HEALTH L. 1, 3(2012); Nadia N. Sawicki, Patient Protection and Decision-Aid Quality: Regulatory and Tort Law Approaches, 54 ARIZ. L. REV. 621, 630 (2012).

35 Pope \& Hexum, supra note 33.

36 WASH REV. CODE $§ \S 7.70 .060,41.05 .033$ (2014).

37 WASH. REV. CODE $§ 7.70 .060$ (2014).

38 See Pope \& Hexum, supra note 33 , at 73 .

39 Our Proven Solutions Drive Outcomes Central to Your Business, EMMI SOLUTIONS, http://www.emmisolutions.com/index.php/our- 
adopted by the VA Healthcare system in 2004.41 Initial data from a study of the iMedConsent showed positive effects in terms of both patient comprehension and patient engagement. ${ }^{42}$ Pushing the forefront of e-health tools, researchers at Case Western Reserve University are developing the eSMARTT application, which uses digital avatars to help individuals make healthcare decisions. ${ }^{43}$

Efforts are also underway in the research informed consent setting. The Perelman School of Medicine at the University of Pennsylvania initially developed an online informed consent tool, OncoLink, to help cancer patients to understand and feel comfortable enrolling in clinical trials and later expanded it to proton therapy trials. ${ }^{44}$ Other companies are seeking to completely digitize the informed consent process. For example, Mytrus created a new iPad econsent application designed for clinical trials. ${ }^{45}$ Similarly,

solutions (last visited May 14, 2014), archived at http://perma.cc/X7AU2NUM.

40 iMedConsent Informed Consent Solution, DIALOGUE MED., http://www.dialogmedical.com/wp-content/uploads/2011/08/Product_Matrix Sheet-Hosted_and_Enterprise1.pdf, archived at http://perma.cc/D2GZAFBZ.

41 Michael J. Kussman, Veterans Health ADMIN., DeP'T VETERANS AFF., VHA HANDBOOK 1004.05: IMEDCONSENT (2009), available at http://www.va.gov/vhapublications/ViewPublication.asp? pub_ID=1857, archived at http://perma.cc/V7A4-NWVS.

42 Daniel E. Hall et al., The Impact of iMedConsent on Patient Decision-Making Regarding Cholecystectomy and Inguinal Herniorrhaphy, 175 J. SURGICAL RES. 227, 231 (2012).

43 Susan Griffith, New Technology to Guide People Through Healthcare Decisions, THINK (August 8, 2013, 12:14 PM), http://blog.case.edu/think/2013/08/08/new_technology_to_guide_people_t hrough_healthcare_decisions, archived at http://perma.cc/PF7Z-EYUE.

44 Penn-Developed Online Informed Consent Tool Could Boost Number of Patients in Cancer Clinical Trials, PENN MED. (Oct. 3, 2011), http://www.uphs.upenn.edu/news/News_Releases/2011/10/astro-consenttool/, archived at http://perma.cc/N4QK-XFYM; B. E. Rosenbaum et al., An Internet-Based, Multimedia Informed Consent Resource for Proton Therapy Clinical Trials: A Pilot Study, 81 INT'L J. RADIATION ONCOLOGY, BIOLOGY, PHYSICS S572 (2011) available at http://astro2011.abstractsnet.com/pdfs/2754.pdf, archived at http://perma.cc/BX5L-QP7B.

45 Anthony Costello, Mytrus, Mytrus Rolls Out Clinical Research Industry's First Patient-Friendly System for Informed Consent via iPad® 
Consent Solutions has an interactive e-consent tool, ${ }^{46}$ as does Systemedicus. The latter's EduConsent is an interactive clinical trial e-consent iPad system which not only provides information, but it also records the consent process and includes facial recognition and signature capture technology to authenticate documentation. ${ }^{47}$

These new tools are all built upon the current informed consent framework (albeit some with the tweaks of the SDM approach) and raise few questions beyond the ones addressed above. Key concerns remain: assuring quality, facilitating access, and ensuring that the tools are developed using empirical evidence regarding what approaches facilitate understanding and informed consent. This latter point is further complicated by the rise of $\mathrm{e}^{-}$ health substitutes for clinical encounters, discussed below.

\section{B. E-Health Substitutes for Clinical Encounters}

Perhaps more interesting than the use of supplemental decision making tools is the development of e-Health substitutes for traditional clinical encounters. Interest in "medical apps" (a term that appeared around 2007) has increased enormously over the past few years. ${ }^{48}$ The market research company Research2Guidance claims that 247 million mobile phone users downloaded a health related app in 2012,49 and as of March 2013, more than 97,000

Application, MARKET WIRED (Apr. 9, 2012, 8:00 AM), http://www.marketwire.com/press-release/mytrus-rolls-out-clinical-researchindustrys-first-patient-friendly-system-informed-1641376.htm, archived at http://perma.cc/69FU-F69X.

46 Ann Neuer, Informed Consent Goes Digital, UTHEALTH (Aug. 29, 2013), http://www.clinicalinformaticsnews.com/ eCliniqua_article.aspx?id=129295, archived at http://perma.cc/G46MCTJN.

47 See SYSTEMEDICUS ${ }^{\mathrm{TM}}$, http://www.systemedicus.com/ (last visited Apr. 14, 2014), archived at http://perma.cc/V2TN-9TLC.

48 Bill Yates, Google Trends: Data Highlights Medical and Healthcare App Growth, IMEDICALAPPS (Aug. 14, 2013), http://www.imedicalapps.com/ 2013/08/google-trends-medical-healthcare-app/, archived at http:// perma.cc/9CR5-Y28V.

49 Ralf-Gordon Jahns, US\$ 1.3 Billion: The Market for mHealth Applications in 2012, RESEARCH2GUIDANCE (Jan. 25, 2012), 
mobile health applications were listed in 62 app stores. ${ }^{50}$ Apple's app store, for example, lists 13,000 health apps. ${ }^{51}$ Apple has even launched an "Apps for Healthcare Professionals" collection within its App Store's Medical Category which covers different sectors like nursing, monitoring, imaging and patient education. Some apps provide basic information for healthcare professionals; others provide resources for patients (including mechanisms to keep track of illness, or provide support for care). Reserach2Guidance projects that the market for mobile healthcare apps services will reach $\$ 26$ billion globally by 2017.52 The technology market research firm ABI Research estimates that the global market could reach 170 million devices by $2017 .{ }^{53}$

A recent survey from the health communications firm Digitas Health indicates that "[a] staggering 90 percent of chronic patients in the US would accept a mobile app prescription from their physician, as opposed to only 66

http://www.research2guidance.com/us-1-3-billion-the-market-for-mhealthapplications-in-2012/, archived at http://perma.cc/9GPB-8ZYP.

50 Research2guidance, Mobile Health Market Report 2013-2017, 3 COM. MHEALTH APPLICATIONS 1, 7 (2013), available at http://www.research2 guidance.com/shop/index.php/downloadable/download/sample/sample_id/26 2/, archived at http://perma.cc/83FR-5VWL; see also Peter McLaughlin \& Melissa Crespo, The Proliferation of Mobile, Devides and Apps for Health Care: Promises and Risks, BLOOMBERG BNA (May 21,2013), http://about.bloomberglaw.com/practitioner-contributions/the-proliferationof-mobile-devices-and-apps-for-health-care-promises-and-risks/, archived at http://perma.cc/7UNN-TTPU.

51 App Store $>$ Medical, ITUNES PREviEW, https://itunes.apple.com/ us/genre/ios-medical/id6020?mt=8\&letter $=\mathrm{H}$ (last visited Apr. 14, 2014), archived at http://perma.cc/H6GV-EE2C.

52 Ralf-Gordon Jahns, The Market for mHealth App Service Will Reach $\$ 26$ Billion by 2017, RESEARCH2GUIDANCE (Mar. 7, 2013), http://www.research2guidance.com/the-market-for-mhealth-app-serviceswill-reach-26-billion-by-2017/.

53 Stephanie Tilenius, Will an App a Day Keep the Doctor Away? The Coming Health Revolution, ForBes (Sept. 8, 2013, 8:30 AM), http://www.forbes.com/sites/ciocentral/2013/09/08/will-an-app-a-day-keepthe-doctor-away-the-coming-health-revolution/; See also Travis Lee Street, Is Healthcare the Future of Mobile Apps?, BIOBEATS (Aug. 19, 2013), http://biobeats.com/2013/08/19/is-healthcare-the-future-of-mobile-apps/. 
percent willing to accept a prescription for medication."54 Happtique, a subsidiary of the business arm of the Greater New York Hospital Association, is working on a system to allow doctors to prescribe apps, which would then be "filled" at app stores by patients. ${ }^{55}$ Government officials in the United Kingdom recently announced that doctors will be encouraged to prescribe smartphone apps to help patients manage conditions ranging from diabetes to depression. ${ }^{56}$

These new mobile apps range from data gathering, to information sharing (between patient and healthcare provider), to actually providing care. One of the pioneers in the prescription-app field is a company called WellDoc. WellDoc has a DiabetesManager system, which "patients can use through a smartphone app, standard cellphone or desktop computer . . . [to collect] information about a patient's diet, blood sugar levels and medication regimen. Patients can enter this data manually or link their devices wirelessly with glucose monitors." 57 This app was one of only a handful of apps that gained clearance from the FDA through their $510 \mathrm{k}$ device clearance process. ${ }^{58}$ In June 2013, at the second annual Digital Health Summer Summit, WellDoc announced the upcoming launch of BlueStar, the first FDA-cleared prescription-only smartphone app for Type 2 Diabetes with insurance reimbursement. ${ }^{59}$

54 Jonah Comstock, Most Patients Want Their Doctors to Prescribe Apps, MOBIHEALTHNEWS (July 1, 2013), http://mobihealthnews.com/ 23418/most-patients-want-their-doctors-to-prescribe-apps/, archived at http://perma.cc/HX7-DT5B.

55 Joshua Brustein, Coming Next: Using an App as Prescribed, N.Y. TIMES (Aug. 19, 2012), http://www.nytimes.com/2012/08/20/technology/ coming-next-doctors-prescribing-apps-to-patients.html?pagewanted=all\&_ $\mathrm{r}=1$ \&, archived at $\mathrm{http}: / /$ perma.cc/ F94C-ZZD4.

56 Murray Wardrop, Doctors Told to Prescribe Smartphone Apps to Patients, THE TELEGRAPH (Feb. 22, 2012, 8:29 AM), http://www.telegraph.co. uk/health/healthnews/9097647/Doctors-told-to-prescribe-smartphone-appsto-patients.html, archived at http://perma.cc/XAK5-H2BY.

57 Id.

$58 \quad I d$.

59 WellDoc Launches BlueStar, First FDA-Cleared, Mobile Prescription Therapy for Type 2 Diabetes with Insurance Reimbursement, BUSINESSWIRE (June 13, 2013, 9:00 AM), http://www.businesswire.com/ news/home/20130613005377/en/WellDoc-Launches-BlueStar-FDA-Cleared- 
According to its website, "BlueStar is intended to provide secure capture, storage, and transmission of blood glucose data as well as information to aid in diabetes selfmanagement. ... In addition, BlueStar provides coaching messages (motivational, behavioral, and educational) based on real-time blood glucose values and trends."60 A few major national employers-including Ford Motor Company, Rite Aid, and DexCom-have already agreed to reimburse employees who use the app through prescription benefit plans. Patients will take the physician's prescription to a pharmacist, who adjudicates the claim and notifies WellDoc. WellDoc then dispatches a staffer to meet with the patient, install the app, and offer training. 61

In another example of efforts in this area, the Veteran Affairs Administration's National Center for PostTraumatic Stress Disorder has been in collaboration with the National Center for Telehealth and Technology ("NCTT") to develop a new genre of mobile apps to assist veterans and active duty personnel (and civilians) who are experiencing symptoms of post-traumatic stress disorder ("PTSD") and traumatic brain injury.62 According to NCTT's website, the key features of the PTSD app include:

- Self-Assessment: Self-assessment of PTSD symptoms with individualized feedback, and ability to track changes in symptoms over time. The assessment does not formally diagnose PTSD.

- System Management: Coping skills and

Mobile-Prescription-Therapy, archived at http://perma.cc/B2N59N9G?type=image.

60 FAQS, WELLDOc, http://www.bluestardiabetes.com/ ?page_id $=347$ (last visited Apr. 19, 2014).

61 Mohana Ravindranath, WellDoc to Release Prescription-Only Smartphone App, THE WASH. POST (June 23, 2013), http://articles.washingtonpost.com/2013-06-23/business/ 40152258_1_appglucose-welldoc, archived at http://perma.cc/D3EM-XLSL.

62 New Mobile App Helps Troops to Self-Manage Behavior, Stress, NAT'L CTR. FOR TELEHEALTH AND TECHNOLOGY, https://t2health.org/ news/new-mobile-app-helps-troops-self-manage-behavior-stress (last visited Apr. 14, 2014), archived at http://perma.cc/6CZP-X3KE. 
assistance for common kinds of posttraumatic stress symptoms and problems, including systematic relaxation and self-help techniques.

- Support: Assistance in finding immediate support. The app enables individuals to identify personal sources of emotional support, populate the phone with those phone numbers, and link to treatment programs. And in an emergency, users can quickly link to the National Suicide Prevention Hotline.

- PTSD Education: Education about key topics related to trauma, PTSD, and treatment. ${ }^{63}$

PTSD Coach Mobile Application has been downloaded 45,000 times in fifty-eight countries, with high consumer satisfaction (according to the ratings in the app store-iOS: 5/5; Android: 4.5/5). It was awarded the Federal Communication Commission Chairman's 2011 AAA award, the 2012 American Telemedicine Association Annual Awards, and named the best federal government app according to NextGov.com. ${ }^{64}$ More than three-quarters of patients found PTSD coach enhanced their understanding of PTSD and its symptoms; helped them find ways to manage those symptoms; made them feel more comfortable seeking support; enabled them to feel they can do something; and allowed them to track problems, find additional resources, and provided practical solutions to problems. ${ }^{65}$

63 PTSD Coach, NAT'L CTR. FOR TELEHEALTH AND TECHNOLOGY, https://t2health.org/apps/ptsd-coach (last visited May 14, 2014), archived at http://perma.cc/5A2S-Q2S8.

64 ATA President's Awards Recipients, AM. TELEMEdicine Ass'N, http://www.americantelemed.org/about-ata/ata-leadership/ ata-awards-recipients (last visited Apr. 19, 2014), archived at http://perma.cc/7WKD-BVQD.

65 PTSD Coach Mobile App Wins the ATA President's Award for Innovation, NAT'L CTR. FOR TELEHEALTH AND TECHNOLOGY, https://2health.org/news/ptsd-coach-mobile-app-wins-ata-presidents-awardinnovation (last visited May 14, 2014), archived at http://perma.cc/BE99YAS. 
Despite the promise of these apps, they are mostly developed without oversight. The FDA recently announced it would regulate only those apps which either are used as an accessory to a regulated medical device or that transform a mobile device into a "regulated device" by sending medical information to care providers. ${ }^{66}$ While the agency was adamant that it would not regulate cell phones and tablets that use the apps, the line between apps and medical devices is becoming less clear. 67

\section{IMPLICATIONS OF THE NEW E-MEDIA FOR INFORMED CONSENT}

There are a number of issues raised by the increasing use of e-health technologies in both the SDM context and the new treatment apps. Development of both areas rests, in part, on similar underlying constructs of autonomy in which the patient need only be provided with enough information (albeit perhaps in better or more

66 Mobile Medical Applications, FOOD AND DRUG ADMIN., $\mathrm{http}: / / \mathrm{www} . \mathrm{fda}$.gov/medicaldevices/productsandmedicalprocedures/conne ctedhealth/mobilemedicalapplications/default.htm (last updated Oct. 22, 2013), archived at http://perma.cc/M9GD-S63Z.

67 Letter from Fred Upton et al., Subcommittee on Oversight and Investigation, to Margaret Hamburg, Commissioner, U.S. Food and Drug Administration (Mar. 1, 2013), available at http://energycommerce.house.gov/sites/republicans.energycommerce.hou se.gov/files/letters/20130301FDA.pdf, archived at http://perma.cc/P8ZATRBT. Besides WellDoc's app, the following devices have FDA approval: AliveCor, which snaps onto the back of a smartphone and turns the device into an EKG and takes cardiac measurements when the user presses the device against the skin near the heart, was classified as a Class II device and issued $510(\mathrm{k})$ clearance12 in November 2012 by the FDA; Welch Allyn, iExaminer Adapter; and Ophthalmoscope, an app and ophthalmoscope that plugs into a smartphone and can detect conditions like retinal detachment and glaucoma, while the accompanying examiner app allows health providers to store the pictures to a patient file or print or email them, received 510(k) clearance for the app in December 2012. December 2012 $510(\mathrm{k})$ Clearances, FOOD AND DRUG ADMIN., http://www.fda.gov/MedicalDevices/ProductsandMedicalProcedures/Devi ceApprovalsandClearances/510kClearances/ucm 334768.htm (last updated Mar. 12, 2014), archived at http://perma.cc/495M-N3CL. 
understandable formats) in order to make a decision. While the SDM model shifts slightly away from the idea of the patient as a unitary decision maker, it still accepts the basic tenet that autonomous choice is possible as long as information is plentiful.

Various studies of traditional informed consent over the years challenge this assumption. Individuals have great difficulty understanding some of the complex information shared in these areas. For example, Peter Schwartz recognizes that "the existence of 'heuristics' and 'biases' in human thought $\square$ hinder the rational processing of quantitative information" on the risks and benefits of a medical intervention. ${ }^{68}$ For example, the majority of the population in the United States (and elsewhere) cannot understand probabilities and frequencies. ${ }^{69}$ Most people use cognitive shortcuts to analyze statistical information, such as giving undue weight to examples they can call to mind most easily (consider the larger fear of airline crashes than car crashes, despite a greater statistical likelihood of the latter). There are biases such as "anchoring and adjustment" (allowing a previous incorrect overestimation of a risk to determine its importance in later decisions), "optimism bias" (assuming you will be the one lucky person when given a description of odds), and "denominator neglect" (failing to consider the overall population when focusing on a serious risk that affects a very small number of people in the group). ${ }^{70}$ Decision aids that provide such quantitative information may be as likely to cause confusion for a decision maker as face-to-face interactions, which also convey such information. As a result, Schwartz argues that we ought to consider how we incorporate quantitative information into decision aids and consider carefully the algorithms that determine which quantitative information patients want. $^{71}$ Similarly, initial research regarding

68 Peter Schwartz, Questioning the Quantitative Imperative: Decision Aids, Prevention, and the Ethics of Disclosure, 41 Hastings CTR. REP. 30 (2011).

69 Id. at 34.

$70 \quad$ Id. at 35.

$71 \quad I d$. at 36. 
"nudging"-also known as "choice architecture"-and informed consent highlights the effect of small differences in the presentation of information (even the order in which something is discussed) on the patient's eventual choice. ${ }^{72}$

These challenges to the traditional model of informed consent raise similar concerns for the use of new technologies as both supplements and substitutes for informed consent. These tools raised additional concerns since the provision of information via e-media may further obfuscate the nuances of information disclosure and potentially increase the effect of any biases. At the very least, more data is needed on the ways in which these tools might influence decision making. For example, do patients give more weight to information provided through these tools? Others have pointed out that the evidence supporting the use of decision making tools does not necessarily "support its potential to reduce overtreatment and costs" in part because of "inadequate consideration of the complexity of how patients construct and express their preferences for treatment."73 Likewise, we do not know whether these tools actually help achieve better informed consent since we lack measurements to determine what actually constitutes better or worse informed consent processes. More information is not always better, nor does it necessarily increase freedom of choice. Furthermore, to the extent that we do have theories that might drive the goals of informed consent, it is not clear that these theories are driving the development of the e-health tools (this may be less true of some of the new comprehensive e-consent frameworks). Moreover, setting standards to achieve quality control is crucial, but without a structure for understanding what measurements of quality to apply it is an almost impossible task. What information to provide and in what format are still key questions for informed consent and we need more

72 See generally Shlomo Cohen, Nudging and Informed Consent, 13 AM. J. BIOETHICS 3 (2013) and accompanying peer commentaries.

73 Steven Katz \& Sarah Hawley, The Value of Sharing Treatment Decision Making with Patients: Expecting Too Much?, 310 JAMA 1559 (2013). 
specific answers than the general approach of "all information" provided in an "understandable format."

Paradoxically, gathering data about the specific uses of the new tools and the implications for patient choice raise additional ethical concerns. There is little evidence regarding the type and extent of data collection that happens behind the scenes in health apps. Many companies may view the data they gather as a proprietary resource, to be used for the further development of e-media tools. Few people provide fully informed consent to the use of their information garnered from apps, medical ones included. Whether or not we should be concerned about the lack of individual consent and control in this area may depend on whether we think the information is used appropriately, and whether we see this data as entitled to protections similar to those given to other types of medical information.

\section{CONCLUSION}

The use of e-health technologies is likely to increase exponentially as more tools are developed. They will continue to play an important role both in supplementing and supplanting clinical encounters. There are significant benefits derived from their adoption, and my goal is not to limit innovation. Nonetheless, it will be important to consider some of the concerns raised by the use of these tools in different contexts and to develop ways to address those concerns in order to prevent later problems. Overall, informed consent will continue to play an important role in healthcare, despite the varying sources of information, but expectations regarding the benefits of the doctrine should be subject to realistic constraints and informed by empirical data about the limits of autonomous medical decision making. Technology moves forward quickly; ethics and evaluation move at a slower pace. It behooves us to work hard to catch up in this context. 